\title{
CENTRALISED SUPPLY OF STERILE MATERIALS IN THE ARMY MEDICAL SERVICES
}

\author{
Colonel W. BARNES, M.B.E., (Retd.)
}

Possibly the first suggestion for the supply of standard packs of sterile dressings to Forward Medical Units on an "as required" basis was made immediately after the 1914/18 war at a meeting of representatives from Field Ambulances and Casualty Clearing Stations. The outcome of this suggestion, however, is not known.

During the 1939/45 war the difficulty of sterilising dressings in the field led in 1942 to the formation in Cairo of a Surgical Dressing Sterilising Unit: In Europe in 1944/45 local schemes were tried for the supply of sterile materials to Divisional Medical Units.

Until 1960 the efficiency of sterilisation of dressings used in military medical units varied greatly as indeed it did in civilian hospitals. In military hospitals autoclaves were available within or adjacent to the operating theatre and standards were considered acceptable, but in some, particularly overseas; the autoclave provided was of the old downward displacement design, normally heated from below by petrol burners. Dressings, clothing and sundries, were packed into autoclave drums by the user and sent to the operating theatre for processing.

Large and small electric " sterilisers" of the boiling type were provided in operating theatres, wards, and medical inspection rooms for the sterilisation of instruments.

Similar equipment was included in the scales of equipment for Field Medical Units such as Field Ambulances, Field Surgical Teams, Casualty Clearing Stations, but the source of heat was methylated spirit burners. Bowl "sterilisers" for Hospitals and Field Units were of the bath type with a strainer and heated by a primus stove.

Drums of autoclaved dressings were provided by military hospitals to medical centres, medical reception stations, and other users, in their areas. These drums were opened as required to remove dressings, which were not wrapped in any way, and were eventually replaced when empty.

The sterility of the drum contents although acceptable in those days was doubtful even as it left the autoclave, but after opening and closure many times the remaining dressings were increasingly contaminated.

In the field no sterile dressings were supplied forward of Field Ambulance Headquarters. In these areas reliance was entirely on factory made and wrapped dressings and cotton wool impregnated with antiseptic such as the First Field Dressings and Shell dressings.

A sterile syringe supply service, using conventional glass syringes, had been in force in Cambridge Military Hospital, Aldershot before 1954. The syringes were placed in "London Hospital" sterilising tubes with a colour code on the outside to show type of syringe and size of fitted needle. Deliveries were made daily to wards and medical centres in the area covered by the hospital. Although not the first project for the supply of sterile items to outside units from a central source it was the first fully organised and maintained service. 
When planning for the Suez landings in 1956 it was decided to put into practice the suggestions made after the 1914/18 war to cover the difficulties of providing autoclaved dressings on board the ships and to medical units on landing. This led to the opening of probably the first genuine Central Sterile Supply (C.S.S.D.) Department in Britain, at the Cambridge Military Hospital. Twin packs were prepared. One pack was made up of caps, gowns, masks, and gloves and the other of drapes. The packs were wrapped in crepe paper and sealed with "Scotch" tape. On completion of autoclaving the packs were removed from the autoclave by personnel wearing sterile gowns, gloves, masks and caps. The packs were then wrapped in bitumen-impregnated paper and sealed with standard sealing tape. Finally the packs were put in pillowcases.

The advantages of this supply system were appreciated and soon the C.S.S.D. had become organised to fill the demand for simple dressings such as swabs and cotton wool balls. These items were contained in the standard commercial paper sweet bags. Deliveries were made daily to the wards. To begin with unused packs from the previous day's deliveries were collected and re-autoclaved, but gradually the system was reduced to a daily "topping" up of holdings in each ward to a pre-determined level.

By 1960 the C.S.S.D. at the Cambridge Military Hospital had been supplied with a modern, high speed, high pressure, high vacuum autoclave and at the same time a smaller version was installed in the theatre of the same hospital. The scope of the CSSD was very quickly extended to include deliveries to all medical centres, medical reception stations and other users covered by the hospital. Later still the scheme was extended to furnish the dressing requirements of The Queen Alexandra Military Hospital, Millbank, The Royal Herbert Hospital, Woolwich, and the Royal Victoria Hospital, Netley. In addition supplies were provided through the Embarkation Medical Officer at Southampton for use aboard the five military troopships. The next demand to be met was for sterile packs containing simple dressing instruments which were processed by the C.S.S.D., and which led to the withdrawal of all ward electric boilers.

Central Sterile Supply Department's were then organised in other military hospitals, at first to meet their own requirements and later to supply dependent units. This was then the situation in 1960.

It was now quite clear that the basic idea of centralised sterilisation had been proved to be feasible and effective and was accepted. Considerable thought was then given to expanding the scope of the scheme and it was agreed that packs should be assembled at the Army Medical Equipment Depot (A.M.E.D.), Ludgershall. Dressings continued to be packed in commercial paper sweet packets and were then sent to the Cambridge Military Hospital for autoclaving and onward distribution.

Irradiation as a method of sterilisation for medical material was relatively new (having been used primarily at the time for the first supplies of disposable plastic syringes). Against civilian counsel it was determined that trials of irradiated dressings should be made. They were distributed to military hospitals throughout the world. The primary wrap of each pack was the paper sweet bag, sealed with an ordinary stapling and enclosed in an outer wrap of heat-sealed polythene sheeting (0.005 in. thickness). These were enclosed in a sealed metal container and irradiated in the spent fuel pond at the Atomic Energy Research Establishment (A.E.R.E.) at Harwell. After irradiation the packs were sent to overseas military hospitals for assay of their climatic shelf life and durability. 
In each hospital one pack of each batch was retained for three months before being returned for sterility testing.

A warning had been received that irradiation of cellulosics would cause denaturing and discolouration, but this was not proven by the trial. The reports were favourable and the sterility testing satisfactory.

A decision was reached to open a dressing packaging department in the A.M.E.D., Ludgershall, which would initially supply simple irradiated dressing packs to all military hospitals in the United Kingdom but at the same time to build up reserve stocks to be held in A.M.E.D. and be available for issue to Field Units as required. All the packs were irradiated in the newly opened Package Irradiation Plant of the A.E.R.E. at Wantage. The initial wrap was still the stapled paper sweet bag overwrapped in polythene. Supplies of these packs were sent to the Cambridge Military Hospital to supplement its output, but gradually pack preparation ceased at that hospital and supply of all its requirements was met from the A.M.E.D.

About this time some special packs were prepared and sent overseas for storage trials. The packs were of two types:-

(a) A parcel of 20 paper bags sealed in bulk in polythene sheeting.

(b) Single paper packets each sealed in a polythene bag.

These packs were distributed to medical units throughout the Near, Middle, and Far East where the climates ranged from hot/dry to hot/wet, but no packs were sent to cold climates.

All packs were retained at their destinations for six months, then one of the parcels (a) was opened and three of its paper bags returned at weekly intervals for sterility testing of the contents. This continued until all trial packs had been returned to Ludgershall. Single paper packets (b) were returned at monthly intervals until all had been received back. In all packs returned no evidence of contamination was found.

The first hospital to be supplied had been the Cambridge Military Hospital but the scheme had been so well received that improvements and expansion followed quickly. The paper sweet bag was replaced by a high quality water repellent paper bag sealed by heat (thermo-seal). Experience had indicated the optimal number of primary packs that could be overwrapped as a bulk pack in polythene. In the A.M.E.D. additional packaging aids were introduced; rotary sealers replaced hand sealers, more staff were recruited and a specially prepared clean area was set aside for pack production. It was only logical that a Staff Sergeant (State Registered Nurse) should be put in charge of the Department as hitherto nursing staff, especially in the theatre, had been responsible for the preparation and autoclaving of dressings and instruments for ward and theatre use.

Although the number and distance of hospitals being supplied multiplied rapidly no great change in the content or variety of packs took place until about 1965 . The packs remained simple in composition varying mainly in the number of individual items. Supply was made against monthly demand as for any other medical equipment. Despatch was made by routine rail and sea movement, except for occasional air despatch of urgently required stores.

The first multiple pack still only contained dressings and was a simple ward dressing pack containing cotton wool balls, gauze swabs and an absorbent dressing pad. 
In military hospitals with a C.S.S.D. traffic was two way. Sterile packs, many containing instruments, were sent out daily to wards, and departments, and the dirty instruments returned to the C.S.S.D. after use. This daily activity lead to gradual deterioration of instruments and to considerable loss.

\section{Theatre Sterile Supply Department}

In 1965 a suggestion was made that if all the requirements of hospital wards and departments could be met by disposable items from a central source it would be possible to set up in a hospital a Theatre Sterile Supply Department concerned only with the supply of sterilised items to theatre, maternity and casualty departments following the experience reported from the Edinburgh Royal Infirmary. This would put all instruments under the care of trained theatre staff which would ensure their greater care, and by greatly restricting movements, would reduce losses. After careful consideration it was decided to carry out a full scale trial of the scheme at the Royal-Herbert-Hospital, Woolwich.

A Theatre Supply Unit was to be established and was to be responsible for all items required in the theatre, maternity and casualty departments. Special items were also prepared for departments and wards, otherwise sterile procedure packs were to be prepared in A.M.E.D. Ludgershall. A great deal of preparatory work had to be done not only in deciding pack contents and quantity of packs but in the training of the staff in the idea and ways that the new packs would be required. In A.M.E.D., Ludgershall bulk purchases were made of totally disposable components for lumbar punctures, spinal injections, ante-natal packs, post-natal packs, manometer readings and so on. Sufficient packs were made to make an initial issue to meet requirements for three months based on estimates of usage. On the day the trial was to start all conventional supplies were withdrawn from the wards. At the end of each month packs used were replaced.

At a meeting held in Woolwich after six months trial only minor criticisms of pack contents were received, for example, "let us have three pairs of forceps instead of two ", and the system was accepted as established. Since then many new packs have been added for special purposes and many other hospitals have adopted the scheme, but much remains to be done.

Over the years supplies have been sent to units in Borneo and used on many defence exercises. In addition the packs were used by British Army medical units sent to help during the floods in British Honduras. They have been supplied to adventure parties including a party led by Sir John Hunt over the Pindus mountains and various expeditions to Greenland. They have invariably been well received.

\section{General}

In the British Army overseas distribution and storage until required of sterilised dressings and instruments would only be possible with a method offering freedom from damage during conveyance, freedom from insect penetration and contamination during storage and retention of sterility during shelf life. Experience has shown that this can be achieved by:-

(a) Initial wrapping of the dressings in a high quality paper bag such as "Thermo Top ", and 
(b) bulk wrapping of the packs in heat sealed polythene sheeting of a minimum gauge of 0.005 in.

Irradiation has now become the only and essential method of sterilisation enabling packaging to be completed before sterilisation takes place. Experience over many years and storage details in every type of climate environment has also shown that:-

(a) The polythene sheeting offers reliable physical protection during conveyance.

(b) Polythene sheeting is unattractive to insects such as ants, beetles and " woolly bears " (Anthrenus) and so allows storage of stockpiles in all climates.

(c) Irradiated packs remain sterile as long as the outer polythene wrap remains intact.

Following the trial of operative procedure packs in Woolwich the contents of the packs became quite varied and included items made from many plastics, mainly polystyrenes, which could not be autoclaved and so the necessity for sterilisation by irradiation was underlined.

There is no doubt that the sterilisation of dressings required in a hospital could be carried out locally by autoclaving, but this method is not suitable for the sterilisation of procedure packs containing a variety of materials and overwrapped in polythene. This type of pack is essential in the Services when instant security and disaster relief operations have to be mounted. The availability of a supply of pre-sterilised procedure packs and dressings makes all units operational immediately. This has been demonstrated many times and never better than during the floods in British Honduras in 1965. Additionally, as items such as disposable drapes,' sheets, pillow slips and clothing become available for medical units these could all be wrapped likewise and the sterilisation facilities of the units concerned restricted to essential instruments, thus considerably reducing the weight for the initial airlift.

\section{Acknowledgements}

My thanks are due to the following for making many valuable additions and comments which made this paper possible:-Lieutenant-General Sir Alexander Drummond, K.B.E., C.B., Major-General J. M. Matheson, O.B.E., T.D., LieutenantColonel R. Freeman, O.B.E. and W.O.II S. R. Collantine. 